\title{
WHICH CHEST COMPRESSION TECHNIQUE IS MORE FATIGUING FOR RESCUER?
}

\author{
Jesus Blanco ${ }^{1}$, Marcin Madziala ${ }^{2}$, Patrycja Szalast ${ }^{2}$ \\ ${ }^{1}$ Hospital Universitario La Paz, Madrid, Spain \\ ${ }^{2}$ Lazarski University, Warsaw, Poland
}

Disaster Emerg Med J 2018; 3(4): 150-151

\section{To the Editor,}

Cardiopulmonary resuscitation is one of the main skills that should be acquired by the medical personnel and emergency personnel, including firefighters. The quality of chest compressions includes not only of the depth and frequency but also the degree of complete chest relaxation after compression and the correct position of the hands on the chest while performing indirect heart massage [1]. The 2015 American Heart Association guidelines place a great emphasis on minimizing pauses during chest compressions [2]. Therefore, based on the aforementioned guidelines, it is reasonable to perform CPR with continuous chest compression, while maintaining the airway patency with endotracheal intubation [3] or with the use of supraglottic airway device $[4,5]$. For people without the experience in the endotracheal intubation, the alternative is to intubation is the use of supraglottic airway devices. This allows for protecting the airways without the need for interrupting chest compressions. An additional issue which should be highlighted is the insufficient quality of chest compressions as reported by many authors [6-8]. The solution to this problem may be to increase the physical fitness in people who perform resuscitation $[9,10]$, as well as further research for the most optimal method of chest compressions.

The aim of the study was to assess the impact of performing two different adult CPR techniques have on the firefighters.

This study was a randomized, cross-over study. After presenting the aims and objectives of the study, 40 firefighters who work in the State Fire
Service were included. All participants of the study had previously been trained in the qualified first aid, including cardiopulmonary resuscitation, maintenance of airway patency and ventilation support. During the study, the participants were asked to conduct cardiopulmonary resuscitation in two different research scenarios. The scenario I included resuscitation based on the standard sequence of 30 chest compressions and 2 rescue breaths, while Scenario II was based on continuous chest compression. Even though the guidelines for CPR recommend that the person who performs chest compressions is changed every 2 minutes, it was decided that in this experimental study to use the rotation time of 5 minutes in order to assess the point at which the quality of chest compressions deteriorates due to the rescuer's fatigue. Both the order of participants and the research methods were determined by the coin throwing technique. Resusci Anne Simulator (Laerdal, Stavanger, Norway) was used to simulate a patient requiring cardiopulmonary resuscitation.

The mean age of firefighters was $28.9 \pm 3.1$ years and the mean work experience in the State Fire Service was $7 \pm 3.7$ years. The average chest compressions frequency during the scenario I was $125 \pm 9 \mathrm{com}$ pressions per minute (CPM) vs. $129 \pm 11$ CPM for Scenario II $(p=0.119)$. The depth of chest compressions during scenarios I and II was different and it was $45 \pm 7 \mathrm{~mm}$ vs. $48 \pm 7 \mathrm{~mm}$ for Scenario I and II, respectively $(p=0.218)$. During the Scenario I, the reduction in depth of compression of the chest occurred in the 4th minute, while it occurred a minute earlier during Scenario II ( $p=0.023)$. 
To sum up, our study material showed that performing the continuous chest compressions is more tiring than the standard 30:2 sequence. However, during the first three minutes of CPR, the chest compressions are deeper.

\section{REFERENCES:}

1. Wieczorek W, Kaminska H. Impact of a corpuls CPR Mechanical Chest Compression Device on chest compression quality during extended pediatric manikin resuscitation: a randomized crossover pilot study . Disaster Emerg Med J. 2017; 2(2): 58-63, doi: 10.5603/DEMJ.2017.0012.

2. Kleinman ME, Brennan EE, Goldberger ZD, et al. Part 5: Adult Basic Life Support and Cardiopulmonary Resuscitation Quality: 2015 American Heart Association Guidelines Update for Cardiopulmonary Resuscitation and Emergency Cardiovascular Care. Circulation. 2015; 132(18 Suppl 2): S414-S435, doi: 10.1161/CIR.0000000000000259, indexed in Pubmed: 26472993.

3. Szarpak L, Karczewska K, Evrin T, et al. Comparison of intubation through the McGrath MAC, GlideScope, AirTraq, and Miller Laryngoscope by paramedics during child CPR: a randomized crossover manikin trial. Am J Emerg Med. 2015; 33(7): 946-950, doi: 10.1016/j. ajem.2015.04.017, indexed in Pubmed: 25937380.

4. Szarpak L, Truszewski Z, Vitale J, et al. Exchange of supraglottic airways for endotracheal tube using the Eschmann Introducer during simulated child resuscitation: A randomized study comparing 4 devices. Medicine (Baltimore). 2017; 96(26): e7177, doi: 10.1097/ MD.0000000000007177, indexed in Pubmed: 28658109.
5. Szarpak Ł, Kurowski A, Truszewski Z, et al. Comparison of 4 supraglotttic devices used by paramedics during simulated CPR : a randomized controlled crossover trial. Am J Emerg Med. 2015; 33(8): 1084-1088, doi: 10.1016/j.ajem.2015.04.050, indexed in Pubmed: 25963675.

6. Kurowski A, Szarpak $Ł$, Bogdański $Ł$, et al. Comparison of the effectiveness of cardiopulmonary resuscitation with standard manual chest compressions and the use of TrueCPR and PocketCPR feedback devices. Kardiol Pol. 2015; 73(10): 924-930, doi: 10.5603/KP.a2015.0084, indexed in Pubmed: 25985725.

7. Truszewski Z, Szarpak L, Kurowski A, et al. Randomized trial of the chest compressions effectiveness comparing 3 feedback CPR devices and standard basic life support by nurses. Am J Emerg Med. 2016; 34(3): 381-385, doi: 10.1016/j.ajem.2015.11.003, indexed in Pubmed: 26612703.

8. Smereka J, Szarpak L, Smereka A, et al. Evaluation of new two-thumb chest compression technique for infant CPR performed by novice physicians. A randomized, crossover, manikin trial. Am J Emerg Med. 2017; 35(4): 604-609, doi: 10.1016/j.ajem.2016.12.045, indexed in Pubmed: 28040386.

9. Kaminska $H$, Wieczorek W, Matusik $P$, et al. Factors influencing high-quality chest compressions during cardiopulmonary resuscitation scenario, according to 2015 American Heart Association Guidelines. Kardiol Pol. 2018; 76(3): 642-647, doi: 10.5603/KP.a2018.0003, indexed in Pubmed: 29313566.

10. Abelairas-Gómez C, Barcala-Furelos R, Szarpak $Ł$, et al. The effect of strength training on quality of prolonged basic cardiopulmonary resuscitation. Kardiol Pol. 2017; 75(1): 21-27, doi: 10.5603/KP.a2016.0165, indexed in Pubmed: 27878801. 